\title{
Scallops, fenestrations, CHIMPS, and other monkey business
}

\section{S. Chris Malaisrie, MD}

\author{
From the Bluhm Cardiovascular Institute of Northwestern Memorial Hospital and Division of Cardiac Surgery at \\ Northwestern University, Chicago, Ill. \\ Disclosures: S. Chris Malaisrie is a consultant and speaker for Medtronic and a speaker for Bolton. \\ Received for publication July 14, 2016; accepted for publication July 14, 2016; available ahead of print Aug 21, \\ 2016. \\ Address for reprints: S. Chris Malaisrie, MD, Division of Cardiac Surgery, Bluhm Cardiovascular Institute, $201 \mathrm{E}$ \\ Huron St, Suite 11-140, Chicago, IL 60611-2908 (E-mail: cmalaisr@nm.org). \\ J Thorac Cardiovasc Surg 2016;152:1229 \\ $0022-5223 / \$ 36.00$ \\ Copyright (C) 2016 by The American Association for Thoracic Surgery \\ http://dx.doi.org/10.1016/j.jtcvs.2016.07.037
}

The coverage of branch vessels during thoracic endovascular aortic repair (TEVAR) with resultant end-organ ischemia is a limitation of endograft technology. Although coverage of the left subclavian artery (LSA) initially was thought to be safe (zone 2 TEVAR), experience has shown that LSA ischemia comes at the cost of permanent stroke and spinal cord injury and reversible complications of arm claudication and vertebrobasilar ischemia. Preserving flow to the LSA in the acute setting remains a clinical dilemma because the emergency nature of the procedure often precludes timeconsuming efforts to preserve LSA flow.

Expediency is an important factor in deciding between options to maintain LSA flow. Prophylactic LSA revascularization and premanufactured fenestrated or branched grafts are best reserved for elective cases. Physician modification of commercially available endografts with creation of scallops or fenestrations and placement of parallel covered endografts (chimneys, parascopes, and snorkels [CHIMPS]) are techniques potentially amenable during emergency cases.

Canaud and colleagues ${ }^{1}$ from Montpellier, France, describe their single-center experience with 10 patients with acute aortic syndromes, including complicated type $\mathrm{B}$ aortic dissections (impending rupture and malperfusion) and traumatic blunt aortic injury treated with zone 2 TEVAR (landing zone proximal to the LSA). Eight of 10 patients were treated with a modified commercially available endograft to preserve LSA flow.

At the heart of the article is the back-table technique of creating the scalloped endograft. Detailed analysis of preoperative imaging allowed the authors to create a scallop on a commercially available endograft, tailored to the patient's anatomy. The size of the scallop, itself, was equal to the size of the LSA orifice plus an additional 5-mm radius. Attachment of radio-opaque markers facilitates the proper alignment of the endograft during deployment under fluoroscopy. The impressive expediency of creating the modification, which the authors report as only 15 minutes, increases the practicality of this approach during emergency procedures.

Although their results are excellent with patency of the LSA in all patients ( 1 of 8 patients demonstrated a $50 \%$

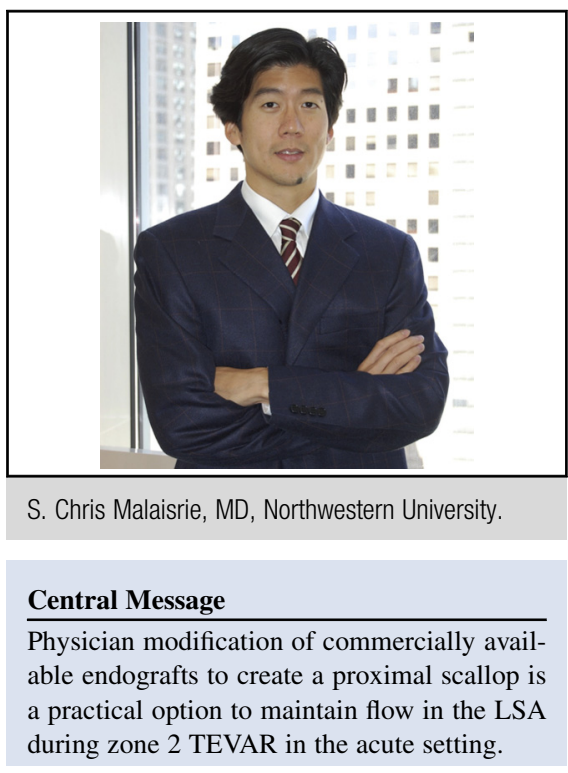

See Article page 1301.

stenosis) and no type 1 endoleaks, Canaud and colleagues do not report their rate of secondary intervention. Indeed, careful inspection of the central figure of the article shows the presence of a second endograft with a zone 3 landing, suggesting that a single scalloped endograft may not be sufficient. In addition, not all patients were candidates for the scalloped endograft because 2 of 10 patients were excluded because of insufficient rotational landing zone in relation to the scallop itself.

Finally, Canaud and colleagues ${ }^{1}$ properly defer the clinical implication of potential zone 1 and zone 0 landings using their scalloped endograft technique. However, the issue remains pertinent because their detailed description can easily be reproduced to perform more proximal arch deployments with or without neck vessel debranching. With these encouraging results, they have opened the door to off-label arch TEVAR.

Canaud and colleagues ${ }^{1}$ describe an expedient technique to preserve LSA flow using a physician-modified endograft during zone 2 TEVAR in the acute setting. Is it a glimpse into the future or just more monkey business?

\section{Reference}

1. Canaud L, Gandet T, Khantalin I, Ozdemir BA, Marty-Ané CH, Alric P. Homemade proximal scalloped stent graft for thoracic endovascular aortic repair of zone 2 acute aortic syndrome. J Thorac Cardiovasc Surg. 2016;152: 1301-6. 